\title{
Trials and tribulations with VH replacement
}

\section{Wenzhao Meng ${ }^{1}$, Sahana Jayaraman ${ }^{1}$, Bochao Zhang ${ }^{2}$, Gregory W. Schwartz ${ }^{2}$, Robert D. Daber ${ }^{1,3}$, Uri Hershberg ${ }^{2,4}$, Alfred L. Garfall ${ }^{5}$, Christopher S. Carlson ${ }^{6}$ and Eline T. Luning Prak ${ }^{1 *}$}

\author{
${ }^{1}$ Department of Pathology and Laboratory Medicine, Perelman School of Medicine, University of Pennsylvania, Philadelphia, PA, USA \\ ${ }^{2}$ School of Biomedical Engineering, Science and Health Systems, Drexel University, Philadelphia, PA, USA \\ ${ }^{3}$ Center for Personalized Diagnostics, University of Pennsylvania Health System, Philadelphia, PA, USA \\ ${ }^{4}$ Department of Microbiology and Immunology, College of Medicine, Drexel University, Philadelphia, PA, USA \\ ${ }^{5}$ Division of Hematology-Oncology, Department of Medicine, Perelman School of Medicine, University of Pennsylvania, Philadelphia, PA, USA \\ ${ }^{6}$ Public Health Sciences Division, Fred Hutchinson Cancer Research Center, Seattle, WA, USA
}

\section{Edited by:}

Zhixin Zhang, University of Nebraska Medical Center, USA

\section{Reviewed by:}

Paolo Casali, University of Texas Health Science Center, USA

Zhixin Zhang, University of Nebraska

Medical Center, USA

\section{*Correspondence:}

Eline T. Luning Prak, Department of Pathology and Laboratory Medicine,

Perelman School of Medicine,

University of Pennsylvania,

Philadelphia, PA 19104, USA

e-mail: luning@mail.med.upenn.edu
$\mathrm{VH}$ replacement (VHR) is a type of antibody gene rearrangement in which an upstream heavy chain variable gene segment $(\mathrm{VH})$ invades a pre-existing rearrangement (VDJ). In this Hypothesis and Theory article, we begin by reviewing the mechanism of VHR, its developmental timing and its potential biological consequences. Then we explore the hypothesis that specific sequence motifs called footprints reflect VHR versus other processes. We provide a compilation of footprint sequences from different regions of the antibody heavy chain, and include data from the literature and from a high throughput sequencing experiment to evaluate the significance of footprint sequences. We conclude by discussing the difficulties of attributing footprints to VHR.

Keywords: $\mathrm{V}(\mathrm{D}) \mathrm{J}$ recombination, $\mathrm{VH}$ replacement, $\mathrm{VH}$, DH, and JH gene segments, receptor editing

\section{CONTEXT, DEFINITION, AND POTENTIAL MECHANISMS OF VH REPLACEMENT}

Antibodies are heterotetrameric proteins comprised of two heavy chains and two light chains that are formed through $\mathrm{V}(\mathrm{D}) \mathrm{J}$ recombination to generate a highly diverse repertoire of antigen binding receptors expressed by $\mathrm{B}$ cells. The recombinase activating gene encoded proteins, RAG1 and RAG2, target conserved heptamer and nonamers within recombination signal sequences (RSSs) to cleave the DNA that flanks recombining gene segments that join together to form the variable regions of antibody heavy and light chains [reviewed in Ref. (1)]. Typical V(D)J recombination generates a signal joint and a coding joint, and the latter is further diversified at the junction between the recombining gene segments by mechanisms including $\mathrm{P}$-addition, $\mathrm{N}$-addition, and exonucleolytic nibbling [reviewed in Ref. (2)]. Occasionally atypical rearrangements occur, generating hybrid joints, open-and-shut joints, or joints between RSSs that ordinarily do not recombine (2-5).

Antibodies can be further revised and diversified through receptor editing of the light chain, somatic hypermutation, gene conversion, and VH replacement (VHR). Receptor editing typically involves RAG-dependent leapfrogging rearrangements on the same allele as the defective or autoreactive light chain, rearrangement on other alleles ( $\kappa$ or $\lambda$ ) and/or RS deletion [which renders preceding $\kappa$ rearrangement non-functional, reviewed in Ref. (6)].

Abbreviations: CDR3, third complementarity determining region; cRSS, cryptic recombination signal sequence; $\mathrm{DH}$, antibody heavy chain diversity gene segment; footprint 5-mer, pentameric nucleotide sequence attributed to VHR; GVHD, graft versus host disease; IgH, antibody heavy chain; $\mathrm{JH}$, antibody heavy chain joining gene segment; RSS, recombination signal sequence; SLE, systemic lupus erythematosus; $\mathrm{VH}$, antibody heavy chain variable gene segment; VHR, VH replacement.
Somatic hypermutation is DNA point hypermutation carried out by activation induced cytidine deaminase (AID) (7), and typically signifies a T-cell dependent antibody response. Gene conversion, in which homologous sequences from other $\mathrm{V}$ genes are grafted into the functional $\mathrm{V}$ gene, is a common method of gene diversification in chickens (8), rabbits and more recent examples have been described in horses and humans (9), and appear to be AIDdependent (10). The final category of antibody gene diversification is VHR, which is the focus of this article. Replacement involves the transfer (or invasion) of some or most of another $\mathrm{V}$ gene into an existing gene rearrangement.

Darlow and Stott have reviewed the literature on VHR and envision two broad mechanistic classes of $\mathrm{V}$ replacement (11). The first, also termed "classical" VHR, consists of invasion of an existing VDJ rearrangement by an upstream VH. In classical VHR there is RAG-mediated cleavage at a cryptic RSS (cRSS) located in the $3^{\prime}$ end of the previously rearranged VH gene. The cRSS has a DNA sequence that differs from the conventional heptamer that flanks the DH gene segment by one nucleotide, bolded in the sequence that follows: $5^{\prime}$-TACTGTG- $3^{\prime}(12)$ and is found in $\sim 70 \%$ of murine VHs and over $90 \%$ of human VHs (13). Occasionally other heptamers containing the $3^{\prime}$ GTG nucleotides can be used, suggesting that the last three nucleotides of the cRSS motif are critical $(14,15)$. The TGT within the cRSS is the codon encoding the conserved cysteine at the junction between FR3 and CDR3. The second class of replacement, according to Darlow and Stott, involves the transfer of other sequences of homology between different $\mathrm{V}$ genes at different sites, many of which appear to also resemble cRSSs. Examples of this second category of VHR have been described in antibodies cloned from single B cells in human tonsils (16), in antibodies cloned from 
synovial tissue of patients with rheumatoid arthritis (17), and in antibodies cloned from human mucosa associated lymphoid tissue lymphomas (18). Alternatively or in addition to RAG-mediated rearrangement, replacements in this second category may arise due to AID-mediated homologous recombination events that are unrelated to the putative cRSSs (11). However, the mechanism of type 2 replacement is far from resolved as recently a non-AID-dependent form of replacement has been described at the $\kappa$ locus using human pre-B cell lines (19). As the molecular mechanism of type 2 replacement remains to be fully elucidated, we will focus the remainder of our analysis in this manuscript on classical VHR (which we refer to hereafter as "VH replacement").

During VHR, an upstream VH gene invades into the cRSS, replacing all but the last few nucleotides of the previously rearranged $\mathrm{VH}$ gene (Figure 1A). The remaining $3^{\prime}$ nucleotides of the $\mathrm{VH}, \mathrm{DH}$, and $\mathrm{JH}$ gene segments are retained in the new rearrangement. The extra nucleotides from the $3^{\prime}$ end of the previous $\mathrm{VH}$ gene are sometimes referred to as a "footprint." Nearly all human VH genes have between five and nine nucleotides in the potential footprint, between the cRSS and the RSS. Most primary RSS rearrangements delete several of these nucleotides from the $3^{\prime}$ end, so the potential footprint may not be easily recognizable. Moreover, during VHR, additional nucleotides can be deleted, so the footprint from the primary $\mathrm{VH}$ can be entirely lost during VHR. It is also possible for more than one replacement rearrangement to occur on the same heavy chain allele, a process referred to as "serial" or "successive" VHR (Figure 1B) (20). An example of a heavy chain rearrangement with more than one footprint sequence is given in Figure 1C.

\section{DEMONSTRATION OF VH REPLACEMENT IN CELL LINES AND MOUSE MODELS}

$\mathrm{VH}$ replacement was initially discovered in two different transformed B cell lines $(12,22)$. In both of these early studies, B cells with non-functional heavy chain gene rearrangements (VDJ-) were able to generate functional heavy chains (VDJ+) by undergoing further heavy chain rearrangement into the cRSS. Continued VHR could also convert a functional VDJ+ rearrangement into a non-functional one through the incorporation of an upstream pseudo-VH gene (12).

The development of antibody heavy chain ( $\mathrm{IgH})$ knock-in mice provided a formal demonstration of VHR in B cells in vivo. VHR was documented in hybridomas derived from the $3 \mathrm{H} 9$ heavy chain knock-in mouse (13). VHR and invasion of upstream DH gene also occurred in a knock-in for the T15 heavy chain (15). Furthermore, $\mathrm{B}$ cells from quasi-monoclonal mice, which have an anti-(4-hydroxy-3-nitrophenyl) acetyl (NP) heavy chain knockin and can only produce $\lambda$ light chains, due to homozygous engineered $\kappa$ deficiency, can lose reactivity to NP by VHR. Strikingly, most secreted antibodies in the quasi-monoclonal mouse appear to arise through VHR (23). VHR was also observed in mice that were genetically engineered to contain two non-productively rearranged heavy chain alleles. In these VDJ-/VDJ- mice, IgHs were generated via VHR in a RAG-dependent manner (crossing the VDJ-/VDJ- mice onto a RAG2 deficient background

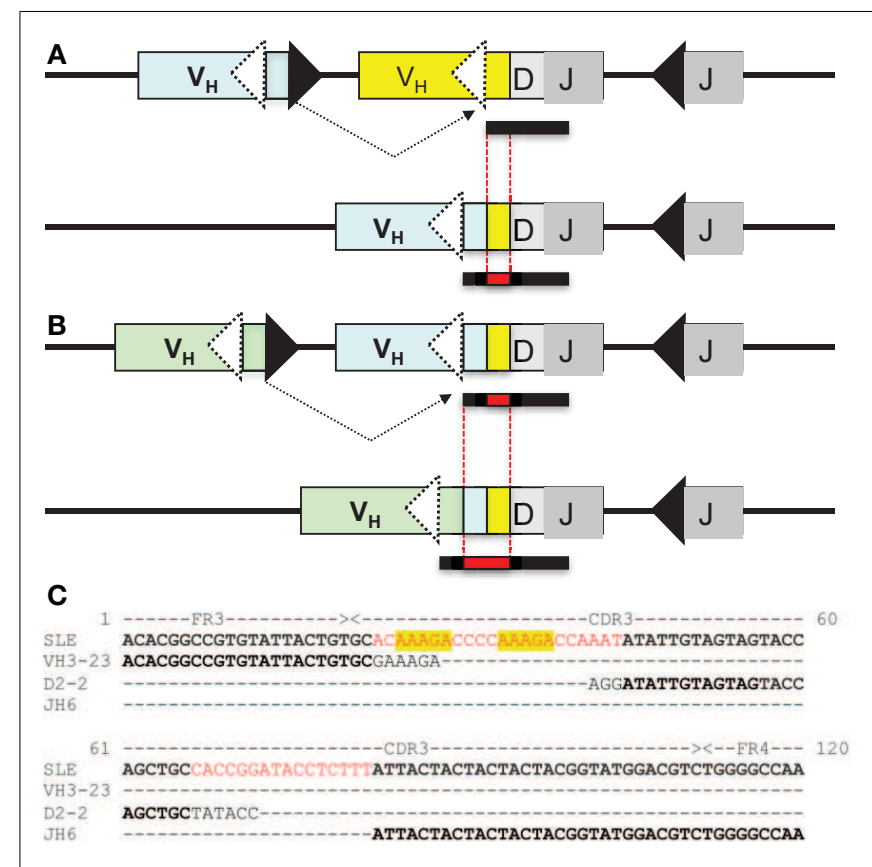

FIGURE 1 | (A) VH replacement: an upstream VH gene invades by rearranging into a pre-existing rearrangement. RAG cleaves the conventional recombination signal sequence (black triangle) of the invading VH (light blue VH gene) and cleaves at a cryptic heptamer sequence (cRSS, dashed white triangle) of the invaded $\mathrm{VH}$ gene (yellow $\mathrm{VH}$ gene). The resulting rearrangement is shown on the second line of the diagram and includes the $\mathrm{DH}$ and $\mathrm{JH}$ genes of the previous rearrangement and the new $\mathrm{VH}$ gene. Also included in the $\mathrm{VH}$ replacement product is a remnant or "footprint" of the preceding VH gene (denoted by a yellow box). Often the products of $\mathrm{VH}$ replacement exhibit CDR3 elongation, due to the retention of the footprint sequence (the CDR3 is indicated by the bar under the sequence and the added length of the new CDR3 sequence including the footprint (in red) is indicated by the black bar below the sequence.) (B) Serial VH replacement. The same conventions are used as in (A) and a longer CDR3 is generated, via the accumulation of footprint sequences. In both panels, boxes denote exons, lines introns, triangles RSS and the rearrangement is indicated by dashed black lines. This diagram is not drawn to scale. (C) Long CDR3 sequence with possible VH replacement(s). Shown is the nucleotide sequence of an expanded $B$ cell clone that was recovered from peripheral blood DNA of a patient with systemic lupus erythematosus (SLE) that reveals a 91 nucleotide CDR3. Kowal et al. described an anti-dsDNA H chain sequence comprised of a VH3-N-DH2-2-JH6, which has similar features to this junction, although it was shorter (21). Sequences in black font match the corresponding germline gene segments. Red font denotes possible $\mathrm{N}$-additions and yellow shading highlights potential footprint sequences. Dashes indicate regions where sequences do not overlap. FR3, framework region 3; CDR3, third complementarity determining sequence; FR4, framework region 4.

resulted in a failure to generate IgM+ B cells) (24). The ability of RAG1 and RAG2 to bind to the cRSS was also demonstrated by electrophoretic mobility shift assays using VH4-34 cRSS versus consensus 12-RSS sequences (25).

In all of the preceding mouse models, VHR conferred greater diversity or functionality upon the $\mathrm{B}$ cell repertoire (i.e., there was a selective pressure that favored VHR). In contrast, when VHR was compared with conventional rearrangement, using a mouse model with an out of frame VDJ rearrangement (VDJ-) that was 
knocked into the heavy chain locus, conventional rearrangement on the other heavy chain allele occurred far more frequently (26). Similarly, in the 56R anti-dsDNA heavy chain knock-in mouse, receptor editing was far more efficient in $\mathrm{B}$ cells that were heterozygous rather than homozygous for 56R (27). One caveat to the 56R study was that cells that had undergone VHR on one allele but were still left with a functional copy of the DNA-reactive 56R heavy chain on the other allele could be counter-selected.

\section{VH REPLACEMENT IN BONE MARROW B CELLS}

To gain further insight into the mechanism of VHR, studies were performed in mice to determine its developmental timing. Several studies suggest that VHR occurs at or near the time of conventional $\mathrm{IgH}$ gene rearrangement. The junctions of $\mathrm{IgH}$ sequences with evidence of VHR in IgH knock-in mice usually contain $\mathrm{N}$ additions (13). Terminal deoxynucleotidyl transferase (TdT), the enzyme that carries out $\mathrm{N}$-addition, is typically expressed at highest levels during $\mathrm{H}$ chain rearrangement in pro- $\mathrm{B}$ and large cycling pre- $\mathrm{B}$ cells (28). Therefore, the presence of $\mathrm{N}$-additions provides indirect evidence that VHR occurred at the time when TdT was active and therefore probably took place in pro-B or early pre-B cells. Further evidence in support of VHR in early stage B cells includes ligation-mediated PCR to measure DNA breaks at the heavy chain locus, which occurred at the highest levels in proB cells (29). These studies suggest that VHR is either occurring in cells where $\mathrm{IgH}$ rearrangement has not yet shut down (failed allelic exclusion) or is driven by pre-BCR rather than BCR signaling, since only the former receptor is expressed at the pre- $\mathrm{B}$ cell stage of development.

With respect to pre-BCR signaling [reviewed in Ref. (30)], it is noteworthy that surrogate light chain knock-out mice have autoreactive antibodies with long CDR3 sequences (31). One potential explanation for this result is that, in the absence of surrogate light chain, the pre-BCR does not assemble and turn off heavy chain rearrangement. Without a heavy chain rearrangement stop signal, there may be higher frequencies of VHR, leading to CDR3 elongation. However, an alternative possibility is that peripheral selection of B cells with long CDR3 sequences is relaxed in the lymphopenic setting that arises due to inefficient primary B cell production in surrogate light chain knock-out mice. It is known that in the absence of normal numbers of peripheral B cells, the level of the B cell survival factor BLyS (also known as BAFF) increases, since B cells are the primary consumers of BLyS. It is also known that the stringency of B cell selection can be reduced when BLyS levels are increased $(32,33)$.

\section{VH REPLACEMENT IN PERIPHERAL B CELLS}

Some studies suggest that VHR could occur in more mature B cell subsets. For example, there are data implicating BCR signaling in VHR in the EU12 human B cell line, which phenotypically resembles IgM+, CD10+, CD $24^{\text {high }}$ cells. In these cells, BCR crosslinking promotes VHR and, conversely, Syk and Src kinase inhibitors inhibit VHR (34). While some of the kinase inhibition experiments could also be influencing mechanisms that operate at earlier stages of B cell development, the BCR crosslinking experiment suggests that BCR signaling could promote VHR in more mature B cells. Furthermore, ligation-mediated PCR experiments documented double-stranded DNA breaks at VH3 cRSS sites in human immature (IgM+, CD27-, CD10+) and mature naïve $(\mathrm{IgM}+, \mathrm{CD} 27-, \mathrm{CD} 10-)$ circulating B cells, also suggesting that VHR may not be limited to immature B cells (34).

Chronic graft versus host disease (GVHD) is one of the most intriguing examples in which VHR could be occurring in more mature B cells (35). B6 mice injected with I-A incompatible T cells from bm 12 mice develop chronic GVHD and produce a spectrum of autoantibodies that resembles those found in systemic autoimmune conditions such as systemic lupus erythematosus (SLE) (36). When anti-dsDNA heavy chain knock-in mice such as $3 \mathrm{H} 9$ and $56 \mathrm{R}$ are used, GVHD occurs and the production of anti-nuclear antibodies is enhanced (35). But the remarkable finding is that among IgG antibodies, a large fraction does not use the knocked in heavy chain (35). Although this unexpected skewing away from the $56 \mathrm{R} \mathrm{H}$ chain could be the result of selective pressures on the minority population of $\mathrm{H}$ chain edited $\mathrm{B}$ cells that emerge from the bone marrow, it is not at all obvious how this selection could operate to disfavor the transgene, and why its effects would be largely confined to IgG and not IgM. It is possible that the transgene was revised (by further gene rearrangement) in the periphery, either because it was inactivated by somatic mutation (37), or because the stimulus afforded by $\mathrm{cGVH}$ re-induced the rearrangement machinery. An alternative explanation is that the $56 \mathrm{R}$ transgene bearing cells are disfavored during primary B cell maturation because they recognize DNA and this self-reactivity causes them to be anergized (this would predict that $56 \mathrm{R}+$ cells would be over-represented amongst IgM rather than IgG B cells). Consistent with the possibility of anergy, most B cells expressing the IgM allotype of the 56R transgene have low levels of $\operatorname{IgM}(38-40)$.

\section{WHAT ARE THE CONSEQUENCES AND POTENTIAL FUNCTIONS OF VH REPLACEMENT?}

$\mathrm{VH}$ replacement allows a $\mathrm{B}$ cell with an inadequate pre-BCR or an autoreactive BCR to swap out the existing heavy chain and replace it with a different heavy chain. But why would this be useful? One possibility is that VHR increases the odds of generating a functional antibody. Producing a functional antibody is rather difficult (41): many rearrangements are out of frame, $\mathrm{VH}$ pseudogenes outnumber functional $\mathrm{VH}$ genes, many newly generated antibodies are autoreactive (42), some combinations may be sequestered inside the cells (38) and some $\mathrm{H}$ and L chain combinations may not pair well with each other. VHR may also facilitate the use of a wider array of upstream VH genes. By giving cells with defective antibody rearrangements a chance at revising those antibodies, perhaps the efficiency of primary B cell generation is greatly improved.

On the other hand, a seemingly diametrically opposed consequence of VHR is the potential generation of multireactive antibodies. VHR can sometimes result in the retention of a "footprint" that is comprised of DNA sequences downstream of the cryptic heptamer of the invaded VH gene (Figure 1). Because the cRSS is typically positioned further from the WGXG motif in the JH segment than the $5^{\prime}$ RSS of a DH segment, VHR is likely to produce longer CDR3 segments than primary rearrangements. Not surprisingly, longer CDR3 sequences have a higher 


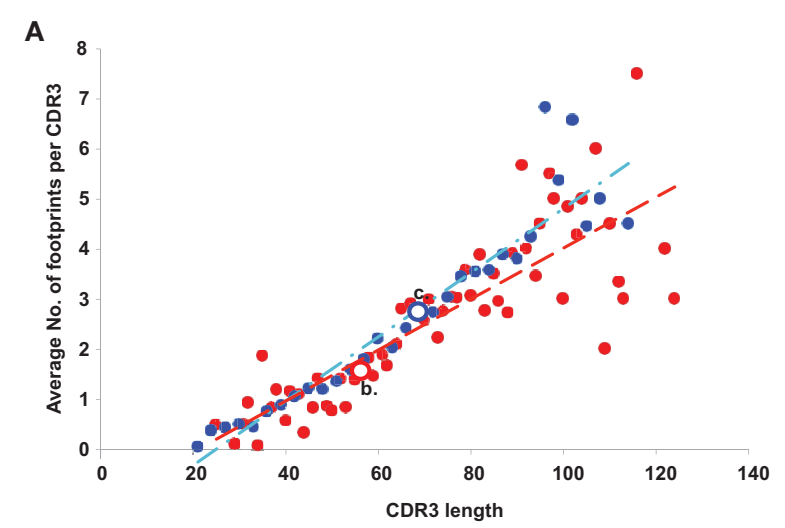

FIGURE 2 | (A) Longer CDR3 sequences have more footprints. Plotted are the average numbers of footprint 5 -mers per sequence. Sequences are averaged at each CDR3 size by the number of sequences that have CDR3s of that particular length. Blue dots are in-frame (IF) rearrangements and red dots are out of frame (OF) rearrangements. We find a positive linear correlation between the length of the CDR3 and the number of footprints $\left(r^{2}=0.89\right.$ for

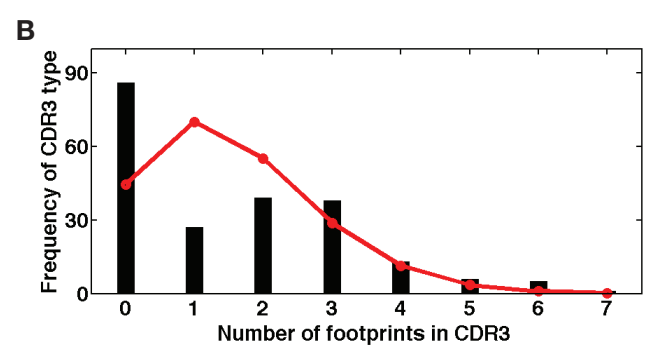

C

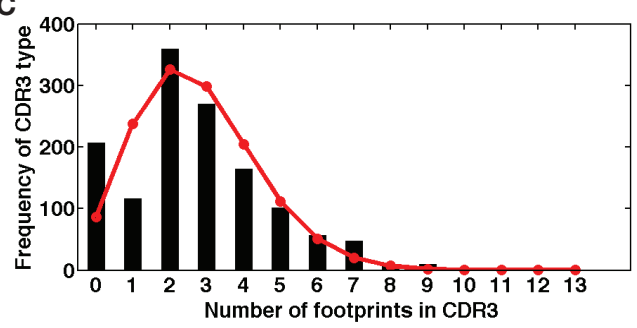

IF, $r^{2}=0.7$ for OF). The line describing this relationship has a slope of $0.06 \pm 0.008$ for OF (red line) and $0.05 \pm 0.008$ for IF rearrangements (blue line). (B,C) are two examples of the entire distribution of footprint numbers at two positions - position 56 (red circle OF) and position 69 (blue circle IF). Black stems indicate the numbers of footprints and red lines represent the fit of a Poisson distribution ( $\lambda=1.57$ and 2.74 , respectively). proportion of footprints (Figure 2), but this does not guarantee that all long CDR3 are the product of VHR. Seventy-eight percent of the potential footprint regions in functional human $\mathrm{VH}$ genes contain an arginine codon, so footprint-containing sequences often also harbor a larger number of charged residues. Longer CDR3s have been associated with greater multireactivity, and such multireactive B cells are normally counter-selected as B cells mature during normal B cell development (42). RA patients have antibodies with unusual CDR3 sequences in their synovium (17) and we have seen CDR3 sequences in patients with SLE that have regions of sequence homology that could arise due to VHR. For example, Figure 1C shows a rearrangement from an expanded B cell clone in a patient with SLE that appears to contain two footprint sequences (highlighted in yellow). Autoimmune-prone strains of mice have elongated CDR3s, although many of these may arise through mechanisms other than VHR, such as D-D fusion $(43,44)$. All of these findings beg the question of whether such "multireactivity" serves a useful function. Is multireactivity protective, particularly in the context of an innate immune response? Or could multireactive antibodies be useful in clearing debris that might be inflammatory if left to accumulate? It is intriguing in this regard that some multireactive IgM antibodies such as the famous T15 idiotype, which binds phosphorylcholine (45), also have anti-inflammatory properties (46).

It is possible that there is no simple single answer to the function of VHR, if it has one at all. It would certainly seem that the biological consequences of VHR depend upon the developmental context in which the rearrangement occurs. If replacement occurs centrally, as is likely to occur in wild type strains of mice such as B6 $(40,47)$, it could serve as a tolerance mechanism (receptor editing) or as means of increasing the efficiency of primary $B$ cell generation. It might also generate a portion of the primary antibody repertoire that has special functional properties such as multireactivity. Conversely, if it occurs peripherally, as might arise in dysregulated states of immune activation such as GVHD (48), perhaps autoimmunity results.

\section{VH REPLACEMENT IN pre-B CELL ALL}

Given the abundance of findings linking VHR to pro- or pre-B cell development discussed above, it is not surprising that the initial demonstrations of VHR occurred in transformed pre-B cell lines. More recently, VHR has been demonstrated to be a major contributor to clonal evolution in precursor $\mathrm{B}$ cell acute lymphoblastic leukemia (B-ALL) $(49,50)$. In B-ALL, there is presumably a large clone of cells "frozen" in the pre-B cell stage. The recombinase machinery remains active in at least some of these cells and can drive VHR. It is instructive to review the early work in the murine pre-B cell line NFS5, in which VHR was found to alter not only the productive but also the non-productively rearranged allele (12). Thus assays where one attempts to define a clone based upon its predicted "conservation" of other immunoglobulin gene rearrangements (such as the other $\mathrm{H}$ chain allele) within the same cell are not necessarily reliable or easy to interpret. The potential for VHR to contribute to intraclonal diversification is highly relevant to the design and interpretation of assays for minimal residual disease monitoring that employ quantitative PCR with probes or primers for clone-specific junctional sequences (51) or, more recently, high throughput sequencing of heavy chain CDR3 (52). Such studies must take VHR and other forms of intraclonal diversification into account. 
Table 1 | Footprint sequences in the $3^{\prime}$ end of human germline VH genes and alleles.

\begin{tabular}{|c|c|c|}
\hline Footprint (5-mer variants) & \multicolumn{2}{|l|}{ VH gene allele(s) } \\
\hline & & VH1-69*4, VH1-69*6, VH1-69*8, VH1-69*9, VH1-69*10, VH1-69*11, VH1-69*12, VH1-69*13, \\
\hline & & VH3-30*1, VH3-30*3, VH3-30*4, VH3-30*5, VH3-30*6, VH3-30*7, VH3-30*9, VH3-30*10, \\
\hline & & VH3-30*11, VH3-30*12, VH3-30*13, VH3-30*14, VH3-30*15, VH3-30*16, VH3-30*17, \\
\hline & & VH3-30*18, VH3-30*19, VH3-33*1, VH3-33*2, VH3-33*4, VH3-33*5, VH3-48, VH3-53*1, \\
\hline & & $\mathrm{VH} 4-28 * 3, \mathrm{VH} 4-30-2 * 4, \mathrm{VH} 4-31 * 1, \mathrm{VH} 4-31 * 2, \mathrm{VH} 4-31 * 3, \mathrm{VH} 4-31 * 10, \mathrm{VH} 4-34 * 9, \mathrm{VH} 4-39 * 2$, \\
\hline & & $\mathrm{VH} 4-39 * 6, \mathrm{VH} 4-39 * 7, \mathrm{VH} 4-4 * 2, \mathrm{VH} 4-4 * 6, \mathrm{VH} 4-4 * 7, \mathrm{VH} 4-59 * 1, \mathrm{VH} 4-59 * 2, \mathrm{VH} 4-61 * 1$ \\
\hline & & $\mathrm{VH} 4-61 * 2, \mathrm{VH} 4-61 * 3, \mathrm{VH} 4-61 * 8, \mathrm{VH} 4 / \mathrm{OR} 15-8, \mathrm{VH} 7-4-1 * 2, \mathrm{VH} 7-4-1 * 4, \mathrm{VH} 7-4-1 * 5$ \\
\hline & CGAGA & $\mathrm{VH} 1-2 * 4, \mathrm{VH} 1-69 * 2, \mathrm{VH} 1-69 * 5, \mathrm{VH} 1 / \mathrm{OR} 15-1 * 1, \mathrm{VH} 3-11 * 3, \mathrm{VH} 3-30 * 8, \mathrm{VH}-30-3 * 1$, \\
\hline & & $\mathrm{VH} 3-53^{*} 2, \mathrm{VH} 3-66^{*} 2, \mathrm{VH} 3-7^{*} 2, \mathrm{VH} 4-28^{*} 4, \mathrm{VH} 4-34^{*} 12, \mathrm{VH} 4-59 * 7, \mathrm{VH} 4-61 * 5, \mathrm{VH} 4-\mathrm{b}$, \\
\hline
\end{tabular}

CGAGAGG (CGAGA, AGAGG)

CGAGACA (CGAGA, GAGAC, AGACA)

CGAGATA (CGAGA, GAGAT, AGATA)

CGAGAAA (CGAGA, GAGAA, AGAAA)

CAAGANA (CAAGA, AAGAN, AGANA)

CAACAGA

CTAGAGA (CTAGA, TAGAG, AGAGA)

CTAGGGA (CTAGG, TAGGG, AGGGA)

CGAAAGA (CGAAA, GAAAG, AAAGA)

CCAGATATA (CCAGA, CAGAT, AGATA, GATAT, ATATA)

CCAGAGA (CCAGA, CAGAG, AGAGA)

TGAAACA (TGAAA, GAAAC, AAACA)

TGAGAGA (TGAGA, GAGAG, AGAGA)

TGAGAAA (TGAGA, GAGAA, AGAAA)

TGAAAGA (TGAAA, GAAAG, AAAGA)

CGGCAGA (CGGCA, GGCAG, GCAGA)

CACGGATAC (CACGG, ACGGA, CGGAT, GGATA, GATAC)
VH1-8, VH4-34*1, VH4-34*2, VH4-34*4, VH4-34*5, VH4-34*13, VH4-59*9

$\mathrm{VH} 3-66 * 4, \mathrm{VH} 4-30-2 * 3, \mathrm{VH} 4-39 * 1, \mathrm{VH} 4-59 * 8, \mathrm{VH} 4-61 * 7, \mathrm{VH} 5-51 * 1, \mathrm{VH} 5-51 * 2$

VH4-34*10, VH4-59*10, VH7-81

$\mathrm{VH} 4-28 * 1, \mathrm{VH} 4-28 * 2, \mathrm{VH} 4-28 * 5, \mathrm{VH} 4-28 * 6$

\section{CAAGANA VH1-45*1}

CAAGATA VH1-45*2

CAAGAGA VH3-13*1, VH3-13*2, VH3-13*4, VH3-74*1, VH3-74*3, VH3/OR16-10*3, VH6-1

CAAGA VH1-45*3, VH3-13*3, VH3-74*2, VH3/OR16-10*1, VH3/OR16-10*2, VH3/OR16-12

CAACAGA VH1-24

CAACA VH1-f*1

CTAGAGA VH1-46*3, VH3-72*1, VH3/OR15-7*5

CTAGA VH3/OR15-7*1, VH3/OR15-7*2, VH3/OR15-7*3

$\mathrm{VH} 3-53 * 3$

CGAAAGA VH3-23*1, VH3-23*2, VH3-23*4, VH3-30*2, VH3-30-3*2, VH3-33*3, VH3-33*6, VH3-NL1 CGAAA $\quad \mathrm{VH} 3-23 * 3, \mathrm{VH} 3-23 * 5$

CGNNN VH4-30-2*2, VH4-31*4,VH4-34*8,VH4-39*5,VH4-59*3, VH4-59*4,VH4-59*5,VH4-59*6,

$C G$ VH $4-31 * 5$

VH3-38

VH4-30-2*1, VH4-30-2*5, VH4-30-4*1, VH4-30-4*2, VH4-30-4*5, VH4-30-4*6, VH4-61*6

TGAAA VH3/OR16-8*1, VH3/OR16-9

TGAAACA VH3/OR $16-8 * 2$

TGAGA VH1/OR15-5

TGAGAGA VH1/OR15-9, VH1/OR21-1

VH3-16, VH3-35

$\mathrm{VH} 3-64 * 3, \mathrm{VH} 3-64 * 5$

VH1-58

VH2-26, VH2-70*1, VH2-70*10, VH2-70*11 
Table 1 | Continued

\begin{tabular}{|c|c|c|}
\hline Footprint (5-mer variants) & VH gene allele(s) & \\
\hline $\begin{array}{l}\text { CATGGAGAG (CATGG, ATGGA, TGGAG, } \\
\text { GGAGA, GAGAG) }\end{array}$ & VH2/OR16-5 & \\
\hline TACGG & $\mathrm{VH} 2-5 * 4, \mathrm{VH} 2-70 * 9$ & \\
\hline TANNN & $\mathrm{VH} 2-5^{*} 7$ & \\
\hline CACGG & $\mathrm{VH} 2-5 * 10$ & \\
\hline CACACAGACC (CACAC, ACACA, & CACACAGACC & $\mathrm{VH} 2-5^{*} 1$ \\
\hline \multirow[t]{2}{*}{ CACAG, ACAGA, CAGAC, AGACC) } & CACACAGAC & $\mathrm{VH} 2-5 * 5, \mathrm{VH} 2-5^{*} 8, \mathrm{VH} 2-5^{*} 9, \mathrm{VH} 2-70 * 12$ \\
\hline & CACACAGA & $\mathrm{VH} 2-5^{*} 6$ \\
\hline $\begin{array}{l}\text { CAAAAGATA (CAAAA, AAAAG, AAAGA, } \\
\text { AAGAT, AGATA) }\end{array}$ & VH3-43, VH3-9 & \\
\hline
\end{tabular}

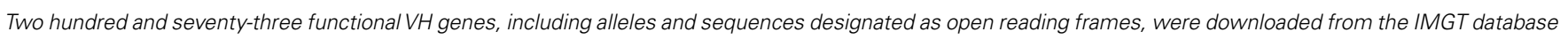
(54) and manually scanned for footprints. A footprint is defined by the nucleotide sequence following the cryptic recombination signal sequence (cRSS), TACTGTG, at the 3 ' end of each VH, and is listed in the left column of the table. The footprint 5-mer variants that were used to scan the sequences are included in parentheses. The right column lists the VH genes and alleles. An asterisk in the VH name refers to a specific allele. If all alleles of a particular VH have the same footprint, allele names are omitted. Overlapping footprints are listed for some footprints in the sub-column on the right. Footprints in red font are also found in germline DH and JH gene segments. Sequences with ambiguous nucleotide designations (N-nucleotides) are indicated by italic font. The following VH gene alleles do not have a cRSS: VH1-18*2, VH1-69*3,VH1-69*7,VH1-C, VH1-f*2,VH2-5*2,VH2-5*3,VH2-70*2, VH2-70*3, VH2-70*4,VH2-70*5,VH2-70*6, VH2-70*7, VH2-70*8, VH2-70*13, $\mathrm{VH} 3-15, \mathrm{VH}-2 \mathrm{O}, \mathrm{VH}-25 * 4, \mathrm{VH}-49, \mathrm{VH}-72 * 2, \mathrm{VH}-73 * 1, \mathrm{VH}-73 * 2, \mathrm{VH}-\mathrm{d}, \mathrm{VH} / \mathrm{OR} 16-13, \mathrm{VH} / \mathrm{OR} 16-6 * 2, \mathrm{VH} 4-30-4 * 3, \mathrm{VH} 4-30-4 * 4, \mathrm{VH} 4-31 * 6, \mathrm{VH}-31 * 7, \mathrm{VH} 4-31 * 8$, $\mathrm{VH} 4-31 * 9, \mathrm{VH} 4-34 * 3, \mathrm{VH} 4-34 * 6, \mathrm{VH} 4-34 * 7, \mathrm{VH} 4-34 * 11, \mathrm{VH} 4-39 * 3, \mathrm{VH} 4-39 * 4, \mathrm{VH} 4-4 * 1, \mathrm{VH} 4-4 * 3, \mathrm{VH} 4-4 * 4, \mathrm{VH} 4-4 * 5, \mathrm{VH} 4-61 * 4, \mathrm{VH} 5-51 * 5, \mathrm{VH}-4-1 * 3$.

\section{ANALYSIS OF VH REPLACEMENT FOOTPRINTS}

The most convincing demonstrations of VHR are those in which a precursor-product relationship can be documented. For example, if the precursor $\mathrm{VH}$ gene is known and then additional $\mathrm{B}$ cells can be found to share most of the $3^{\prime}$ side of the CDR3 (the same DH-JH junction), but have a different $\mathrm{VH}$ gene, this can be compelling, as in B-ALL or in mouse models with heavy chain knock-ins. In contrast, the analysis of VHR in a physiologic and fully diversified immune repertoire has by necessity focused on indirect evidence, namely the enumeration of footprints, which are potential traces of previous VDJ rearrangements in IgH sequence data. In mice, footprints are readily observed in constrained immune repertoires [for example, Ref. (13, 15, 23)]. Footprints are also observed in humans (53). However, a fundamental issue with footprint analysis in humans is one of specificity of attribution: does the footprint arise due to VHR or is it due to some other form of junctional diversification or skewing in the rearrangement process? Or does it occur by chance?

To investigate the hypothesis that footprint sequences are due to the process of VHR, we sequenced IgH rearrangements from peripheral blood $\mathrm{B}$ cells of a healthy human adult subject, following an IRB-approved protocol. We identified 42,221 unique sequences from this sample, which we analyzed for $\mathrm{VH}$ footprints using a sliding window method (see Supplementary Material for further details). All of the potential footprints arising from sequences at the $3^{\prime}$ ends of the germline $\mathrm{VH}$ genes are listed in Table 1. In accordance with their conventional description in the literature (41), we required the footprint to be least five nucleotides long (we hereafter refer to these sequences as footprint 5-mers). If footprint 5-mers are due to VHR, they will have specific characteristics in antibody repertoire data, indicated by the tests described below.

\section{TEST 1: VH REPLACEMENT FOOTPRINTS SHOULD BE LOCATED IN THE 5' END OF THE CDR3 SEQUENCE}

One way to distinguish bona fide footprints from other sources of sequence variation is to compare the number of footprints in the junction between $\mathrm{VH}$ and $\mathrm{DH}$ (referred to as N1) to the number in the junction between $\mathrm{DH}$ and $\mathrm{JH}$ (referred to as N2). Footprints arising via VHR should occur in N1 rather than $\mathrm{N} 2$ because the cryptic heptamer is located in N1. However, as shown in Figure 3A, there is a roughly bimodal distribution of footprint 5-mers. Even though we excluded the most common footprints that were found in the germline DH gene segments (Table 2), there were still plenty of footprint sequences in N1, DH, and N2. In Figure 3B we took the analysis one step further and removed some more of the common footprint sequences that are found not only in the germline $\mathrm{DH}$ gene segments but also in JH6. This resulted in more skewing toward N1, but a large proportion of the footprints were still outside of N1. In fact, not only were footprint 5-mers found in $\mathrm{DH}$ and $\mathrm{JH}$, but they were also found in other parts of the $\mathrm{VH}$ gene. Table 3 lists the positions of all of the footprint 5-mers found amongst the germline $\mathrm{VH}$ alleles listed in the IMGT database.

\section{TEST 2: VH REPLACEMENT FOOTPRINTS SHOULD BE MORE FREQUENT IN UPSTREAM VH GENES THAN DOWNSTREAM VH GENES AND ABSENT FROM VH6-1}

Another requirement for a footprint to be consistent with VHR is that the invading $\mathrm{VH}$ must be upstream of the $\mathrm{VH}$ that donated the footprint. Unfortunately, the recipient VH is often difficult to define because many VHs have the same or very similar footprints 


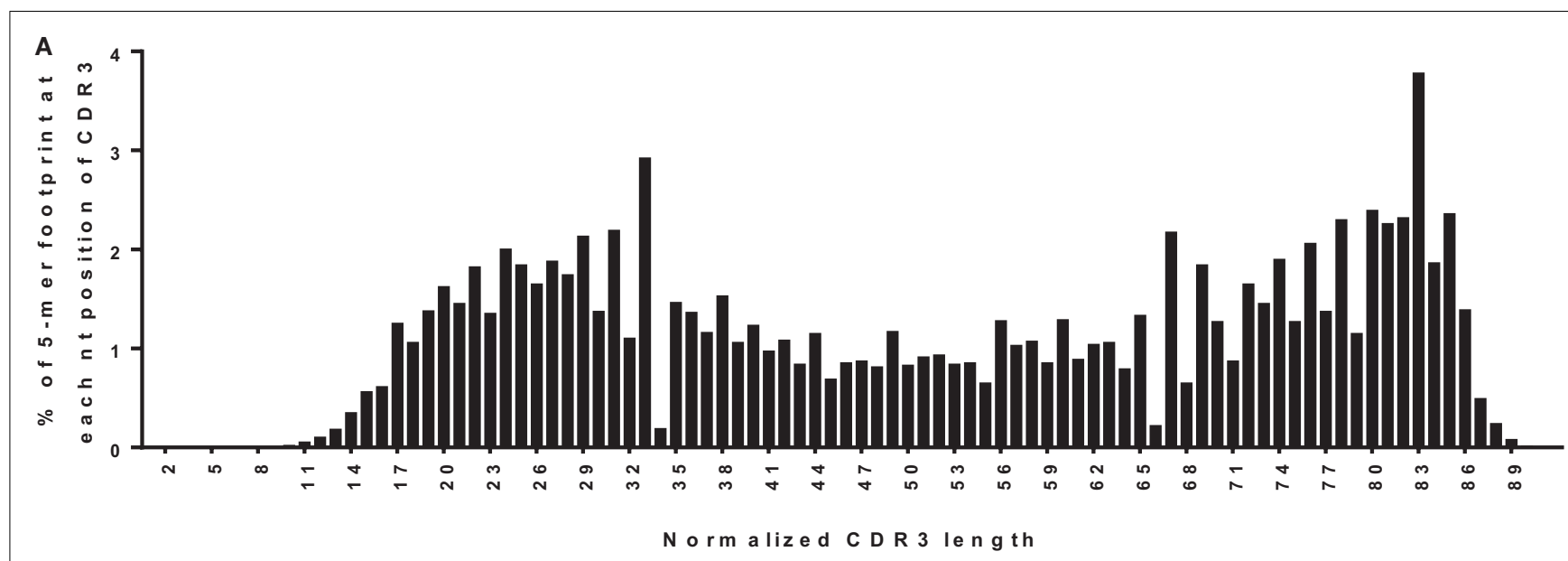

B

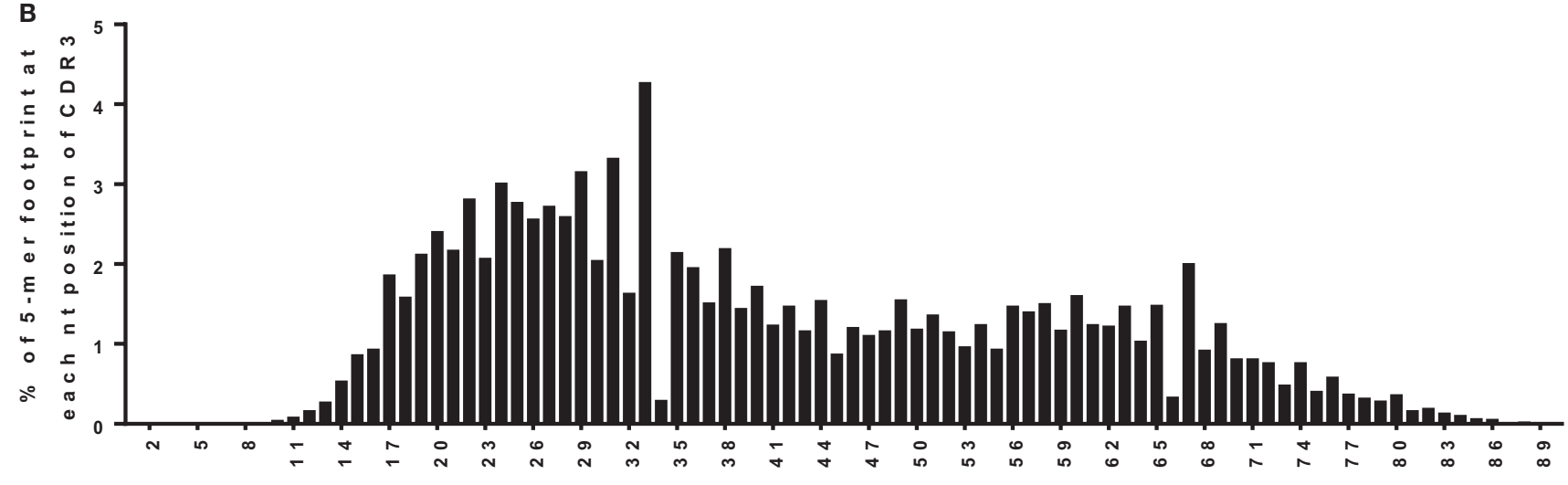

Norm alized CDR 3 length

FIGURE 3 | Positions of footprint 5-mers. (A) Frequency distribution of all footprint 5 -mers out of total unique sequences ( $n=42,221)$ plotted against the normalized CDR3 position. The CDR3 is herein defined to begin at the conserved CAR amino acid sequence (TGT GCG AGA nucleotide sequence) within the $3^{\prime}$ end of $\mathrm{VH}$ and end at the conserved W (TGG nucleotide sequence) that is immediately upstream of the first conserved glycine, GGC nucleotide sequence) within the JH. "TGGAG" is excluded as it is found in many alleles of all DH genes. The position of the footprint is defined by where the footprint starts within the CDR3. For example, if a footprint occupies nucleotides 12-16 of the CDR3, it will be plotted at position 12. CDR3 lengths were normalized to a scale of $1-100$ using $p 1=p /(L \times 100)$; where $p$ is the position of the 5-mer in the real CDR3 sequence, $L$ is the length of the CDR3 sequence, and $\mathrm{p} 1$ is the normalized position. Normalized positions are rounded to the nearest integer. (B) Frequency distribution of all footprint 5-mers plotted against the normalized CDR3 position, corrected for footprint 5-mers in the germline JH6 gene. "ATGGA," "TACGG," and "CATGG" were excluded when found in the $3^{\prime}$ end of the CDR3 within the JH6 gene, as these 5-mers are found in the germline JH6 sequence. Footprint 5-mers found in other $\mathbf{J H s}$ (see Table 2) are not counted in either (A) or (B) because they are all located outside CDR3 region of $\mathrm{JH}$. (see Table 1). However, a more straightforward test of whether a footprint 5-mer represents the product of VHR is to evaluate the frequency of footprints in different $\mathrm{VH}$ rearrangements. In particular, the $3^{\prime}$ most $\mathrm{VH}$ gene (VH6-1, in humans), when rearranged, should not exhibit VHR footprints as there is no downstream $\mathrm{VH}$ that it can invade. Conversely, $\mathrm{VH}$ genes that are situated in the $5^{\prime}$ end of the locus should have higher frequencies of footprints than $3^{\prime} \mathrm{VH}$ genes, if VHR is frequent. Yet the overall frequency of footprint 5-mers was similar amongst unique sequences in all of the most commonly used VHs, including VH6-1 (Figure 4). The frequency of footprints was also not significantly higher in out of frame (unselected) versus in-frame rearrangements (Figure 4A).

We also performed this analysis using immunoglobulin analysis tool (IgAT) software (42) and observed that the frequency of footprints was not reduced in VH6-1 when compared to other VHs (Figure 4B). Lower VH footprint frequencies were observed overall because footprints in the $3^{\prime}$ end of the CDR3 are excluded by the IgAT program (42). One intriguing feature of the IgAT data was that, unlike our footprint analysis that captured 5-mers at both N1 and N2, when only N1 was analyzed, some VHs, including VH6-1, had higher footprint frequencies than others. Since VH6-1 cannot have any footprints due to VHR, we conclude that many footprint 5-mers that are found in the CDR3 do not arise by VHR.

The simplest explanation is that the great majority of 5-mer sequences found throughout the CDR3 resemble footprints by chance. The frequency of footprint 5-mers in the entire CDR3 was highly correlated with the length of the CDR3 (Figure 2). The ability to generate a replacement footprint by chance may be 
Table 2 | Footprint sequences in DH and JH alleles

\begin{tabular}{|c|c|}
\hline DH gene & Sequence (footprint(s) in red font) \\
\hline D1-1*01 & GGTACAACTGGAACGAC \\
\hline D1-14*01 & GGTATAACCGGAACCAC \\
\hline $\mathrm{D} 1-20 * 01$ & GGTATAACTGGAACGAC \\
\hline D1-26*01 & GGTATAGTGGGAGCTACTAC \\
\hline D1-7*01 & GGTATAACTGGAACTAC \\
\hline $\mathrm{D} 2-15^{*} 01$ & AGGATATTGTAGTGGTGGTAGCTGCTACTCC \\
\hline $\mathrm{D} 2-2 * 01$ & AGGATATTGTAGTAGTACCAGCTGCTATGCC \\
\hline $\mathrm{D} 2-2 * 02$ & AGGATATTGTAGTAGTACCAGCTGCTATACC \\
\hline $\mathrm{D} 2-2 * 03$ & TGGATATTGTAGTAGTACCAGCTGCTATGCC \\
\hline $\mathrm{D} 2-21 * 01$ & AGCATATTGTGGTGGTGATTGCTATTCC \\
\hline $\mathrm{D} 2-21 * 02$ & AGCATATTGTGGTGGTGACTGCTATTCC \\
\hline $\mathrm{D} 2-8 * 01$ & AGGATATTGTACTAATGGTGTATGCTATACC \\
\hline $\mathrm{D} 2-8 * 02$ & AGGATATTGTACTGGTGGTGTATGCTATACC \\
\hline D3-10*01 & GTATTACTATGGTTCGGGGAGTTATTATAAC \\
\hline D3-10*02 & GTATTACTATGTTCGGGGAGTTATTATAAC \\
\hline D3-16*01 & GTATTATGATTACGTTTGGGGGAGTTATGCTTATACC \\
\hline D3-16*02 & GTATTATGATTACGTTTGGGGGAGTTATCGTTATACC \\
\hline D3-22*01 & GTATTACTATGATAGTAGTGGTTATTACTAC \\
\hline D3-3*01 & GTATTACGATTTTTGGAGTGGTTATTATACC \\
\hline D3-3*02 & GTATTAGCATTTTTGGAGTGGTTATTATACC \\
\hline D3-9*01 & GTATTACGATATTTTGACTGGTTATTATAAC \\
\hline $\mathrm{D} 4-11 * 01$ & TGACTACAGTAACTAC \\
\hline $\mathrm{D} 4-17^{*} 01$ & TGACTACGGTGACTAC \\
\hline D4-23*01 & TGACTACGGTGGTAACTCC \\
\hline D4-4*01 & TGACTACAGTAACTAC \\
\hline D5-12*01 & GTGGATATAGTGGCTACGATTAC \\
\hline D5-18*01 & GTGGATACAGCTATGGTTAC \\
\hline D5-24*01 & GTAGAGATGGCTACAATTAC \\
\hline D5-5*01 & GTGGATACAGCTATGGTTAC \\
\hline D6-13*01 & GGGTATAGCAGCAGCTGGTAC \\
\hline D6-19*01 & GGGTATAGCAGTGGCTGGTAC \\
\hline D6-25*01 & GGGTATAGCAGCGGCTAC \\
\hline D6-6*01 & GAGTATAGCAGCTCGTCC \\
\hline $\mathrm{D} 7-27^{*} 01$ & CTAACTGGGGA \\
\hline JH gene & Sequence (footprint(s) in red font) \\
\hline \multirow[t]{2}{*}{$\mathrm{J} 1 * 01$} & GCTGAATACTTCCAGCACTGGGGCCAGGGCACCCTGGTC \\
\hline & ACCGTCTCCTCAG \\
\hline \multirow[t]{2}{*}{$\mathrm{J} 2 * 01$} & CTACTGGTACTTCGATCTCTGGGGCCGTGGCACCCTGGTC \\
\hline & ACTGTCTCCTCAG \\
\hline \multirow[t]{2}{*}{$\mathrm{J} 3 * 01$} & TGATGCTTTTGATGTCTGGGGCCAAGGGACAATGGTCACCG \\
\hline & TCTCTTCAG \\
\hline \multirow[t]{2}{*}{$\mathrm{J}^{*} 02$} & TGATGCTTTTGATATCTGGGGCCAAGGGACAATGGTCACCG \\
\hline & TCTCTTCAG \\
\hline \multirow[t]{2}{*}{$\mathrm{J} 4 * 01$} & ACTACTTTGACTACTGGGGCCAAGGAACCCTGGTCACCGTCT \\
\hline & CCTCAG \\
\hline \multirow[t]{2}{*}{$\mathrm{J} 4^{*} 02$} & АCTACTTTGACTACTGGGGCCAGGGAACCCTGGTCACCGTCT \\
\hline & CCTCAG \\
\hline \multirow[t]{2}{*}{$\mathrm{J} 4{ }^{*} 03$} & GCTACTTTGACTACTGGGGCCAAGGGACCCTGGTCACCGTCT \\
\hline & CCTCAG \\
\hline
\end{tabular}

(Continued)

\begin{tabular}{|c|c|}
\hline JH gene & Sequence (footprint(s) in red font) \\
\hline \multirow[t]{2}{*}{$\mathrm{J} 5^{*} 01$} & ACAACTGGTTCGACTCCTGGGGCCAAGGAACCCTGGTCACC \\
\hline & GTCTCCTCAG \\
\hline \multirow[t]{2}{*}{$\mathrm{J}^{*} 02$} & ACAACTGGTTCGACCCCTGGGGCCAGGGA \\
\hline & ACCCTGGTCACCGTCTCCTCAG \\
\hline \multirow[t]{2}{*}{$\mathrm{J} 6 * 01$} & ATTACTACTACTACTACGGTATGGACGTCTGGGGGCAAGGGA \\
\hline & CCACGGTCACCGTCTCCTCAG \\
\hline \multirow[t]{2}{*}{$\mathrm{J} 6 * 02$} & ATTACTACTACTACTACGGTATGGACGTCTGGGGCCAAGGGA \\
\hline & CCACGGTCACCGTCTCCTCAN \\
\hline \multirow[t]{2}{*}{$\mathrm{J} 6 * 03$} & АTTACTACTACTACTACTACATGGACGTCTGGGGCAAAGGGA \\
\hline & CCACGGTCACCGTCTCCTCAN \\
\hline \multirow[t]{2}{*}{$\mathrm{J} 6 * 04$} & ATTACTACTACTACTACGGTATGGACGTCTGGGGCAAAGGGA \\
\hline & CCACGGTCACCGTCTCCTCAG \\
\hline
\end{tabular}

Thirty-four germline functional human DH alleles and $13 \mathrm{JH}$ alleles were downloaded from the IMGT database (54). Each allele was scanned for all of the possible five nucleotide footprint motifs listed in Table 1. Sequences containing five nucleotide footprints are given in red font. In some cases the region matches more than one possible footprint (for example, D5-12*01 contains three different footprints: GGATA, GATAT, and ATATA).

under-appreciated. In a completely random DNA sequence with equal proportions of $\mathrm{A}, \mathrm{T}, \mathrm{G}$, and $\mathrm{C}$ bases, the chance of finding a specific 5 -mer sequence is $1 / 1,024$ (or $\sim 0.001$ ). However, there are at least 50 different footprint-derived 5-mer sequences amongst human VH genes (Table 3), increasing the odds to 50/1,024 $(\sim 5 \%)$. But this calculation ignores the number of different positions along the VDJ rearrangement where the footprint might be detected and on how many variants of the footprint are permitted. If the $5^{\prime}$ end of a CDR3 sequence is 30 nucleotides long, that means that there are 6 completely non-overlapping sequences that have a length of five nucleotides, bringing the minimum likelihood of detection of at least a single footprint in that sequence up to $26 \%\left[1-(1-0.05)^{6}\right]$ or $1-\operatorname{Pr}($ not getting any 5 -mers in the $30 \mathrm{bp}$ sequence). If the base composition of the DNA is non-uniform or the entire CDR3 sequence is surveyed or if sequences with mutations are permitted (for example those matching in 4 out of $5 \mathrm{bp}$ ), the chances of detecting a footprint increase even further.

We also wondered why some $\mathrm{VH}$ genes had higher footprint frequencies in N1 than others (Figure 4B), as this finding is not similar to what one would expect by random chance. We wondered if the real VHR events were hiding somewhere in a large pile of non-VHR footprints. A high "false positive" rate of footprint 5 -mers could come about because of sequencing errors. Alternatively or in addition, it may be easy to create false VHR 5-mer sequences in primary VDJ rearrangements through a combination of $\mathrm{N}$-addition, nibbling (or sequencing deletion) and the $3^{\prime}$ sequence of the VH. For example AAAGA could become AAGA or AGA.

It may be worthwhile to develop a better computational approach for detecting VHR footprints with greater specificity for VHR. The IgAT software already eliminated footprints that match the germline $\mathrm{VH}$ sequence exactly, but this is insufficient, give the 
Table 3 | The number of footprints found in various regions of human VH genes.

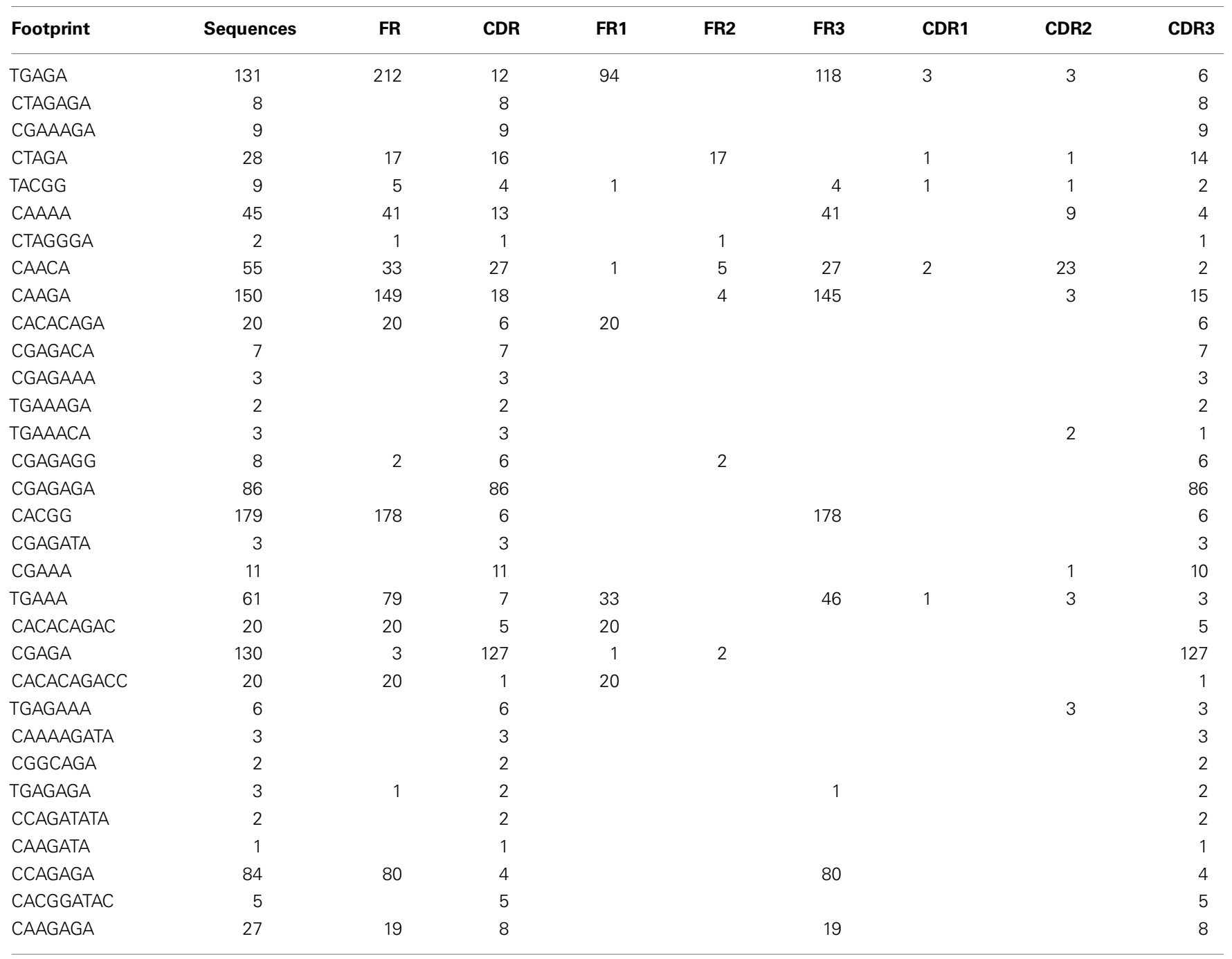

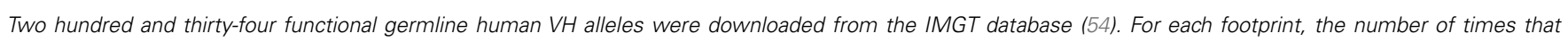
footprint was found in the VH alleles was recorded. The first column lists the footprint, the second column lists the number of alleles in which the footprint is found. Some alleles contain more than one footprint. The remaining columns indicate how many footprints were found in each of the corresponding regions of the $V$ region. FR, framework; CDR, complementarity determining region. The columns named FR and CDR provide the total number of times that a particular footprint is found in the FR or the CDR.

high frequency of footprints in N1 of VH6-1. Further specificity might be achievable if one were to limit the detection of footprint 5 -mers to sequences that are unlikely to arise through a single nucleotide change (for example, those that arise by deletion that converts a non-matching 6-mer to a matching 5-mer, or mutation of a non-matching 5-mer to a footprint 5-mer or $\mathrm{N}$-addition of a nucleotide adjoining a 4-mer to create a footprint 5-mer). An alternative approach is to require that there be two footprintlike sequences in tandem. Either or both of these methods might increase specificity, but could also reduce sensitivity of footprint detection. The validity of either approach would need to be tested further using validated data sets in which VHR events are known to have or have not occurred.

We also considered the possibility that footprint 5-mers may frequently arise through some mechanism other than VHR.
We considered two potential alternative mechanisms - (1) microhomology-mediated joining and (2) cleavage, nibbling, and rejoining at the cryptic heptamer.

\section{ALTERNATIVE THEORY 1: MICROHOMOLOGY-MEDIATED JOINING}

We considered the possibility that footprints at N1 were arising primarily due to microhomology-mediated joining of similar sequences between the $\mathrm{VH}$ and the $\mathrm{DH}$ segments. If microhomology-mediated joining were common, one might expect that $\mathrm{VHs}$ that share the same 5-mers with DHs are more likely to rearrange, but as shown in Figure 5, this is probably not usually the case. DH5-12 (open bars in Figure 5), which has three footprint 5-mers, does not appear to be used more frequently in rearrangements involving $\mathrm{VHs}$ that contain the same 5-mers such as VH2-26 (red arrow). Rather than being 


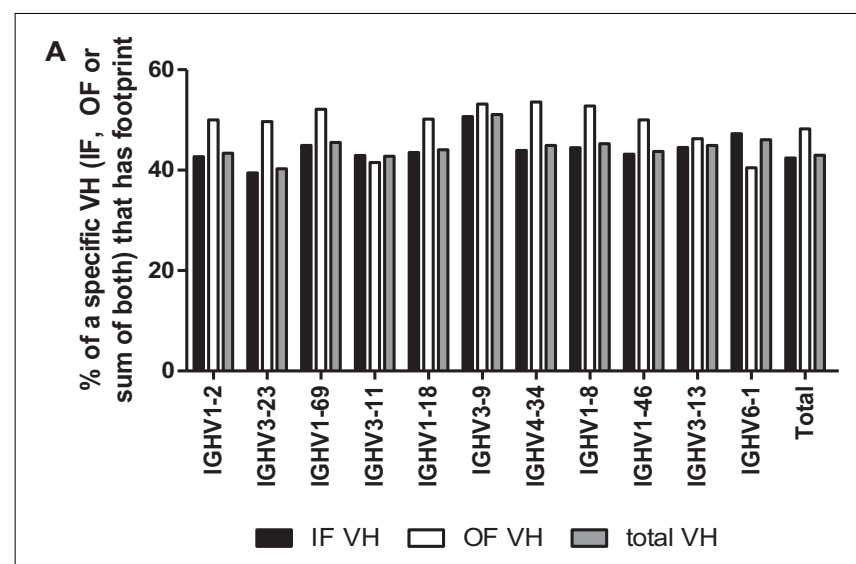

B

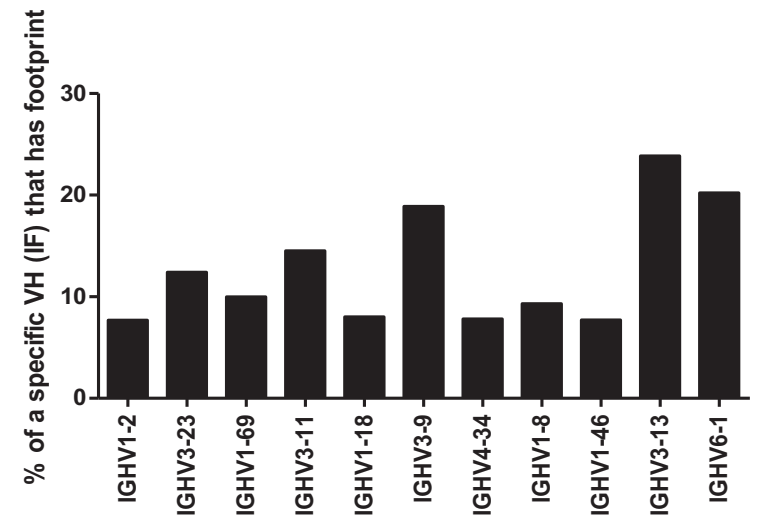

FIGURE 4 | (A) Percentage of rearrangements with footprints for the 10 most frequent $\mathrm{VH}$ rearrangements and $\mathrm{VH} 6$-1. The percentages of rearrangements that contain at least one footprint 5-mer in either (or both) the $5^{\prime}$ end or the $3^{\prime}$ end of the rearrangement are shown for unique rearrangements for each of the 10 most common $\mathrm{VH}$ genes and for VH6-1. CDR3 sequences are defined as described in the legend to Figure $\mathbf{3}$ and normalized to an arbitrary length of 100 . The $5^{\prime}$ end (which almost always contains $\mathrm{N} 1$ ) is defined as the first $20 \%$ of the sequence and the $3^{\prime}$ end is defined as the last $20 \%$ of the sequence (which almost always contains $\mathrm{N} 2$ ). $\mathrm{VH} 6-1$ is the most $3^{\prime} \mathrm{VH}$ gene and cannot contain footprints that are due to $\mathrm{VH}$ replacement. Black bars denote unique rearrangements that are in-frame (IF VH), white bars denote out of frame rearrangements (OF VH), and gray bars indicate total unique rearrangements (total VH). (B) Footprint Frequency of in-Frame VH rearrangements in N1 using IgAT Software. The same unique in-frame (IF) VH rearrangements, as shown in (A), were analyzed for the presence of one or more footprints using IgAT software (2). Plotted are the frequencies of unique IF VH rearrangements that have one or more footprints in the $\mathrm{N} 1$ region.

skewed toward particular VHs with matching or similar footprints, the frequency of rearrangements of different VHs to DH5-12 rearrangements resembled overall VH usage (Figure 5, closed bars). While this analysis is very preliminary and only focused on a single $\mathrm{DH}$, it suggests that microhomology-mediated joining, based upon shared sequences between $\mathrm{VH}$ and $\mathrm{DH}$, is not a frequent mechanism for generating footprint 5-mers.

\section{ALTERNATIVE THEORY 2: CLEAVAGE, NIBBLING, AND REJOINING AT THE CRYPTIC HEPTAMER IN VH}

We wondered if there could be cleavage at the cryptic heptamer, followed by exonucleolytic nibbling and re-sealing at the site of the break, without full-blown rearrangement (Figure S1 in Supplementary Material illustrates this idea for a VH6-1 rearrangement). Note that this type of rearrangement product would not involve VHR, but would have the result of diversifying the $3^{\prime}$ end of the $\mathrm{VH}$ in the primary rearrangement product, altering the primary amino acid sequence and/or the reading frame of the rearrangement. This hypothesis makes predictions regarding the sequence characteristics that would be more or less amenable to this type of atypical open-and-shut joint (2). For example, one would expect that if most footprint 5-mers at $\mathrm{N} 1$ arise by this mechanism, that the frequency of footprint 5-mers would be very low in $\mathrm{VH}$ genes that lack cryptic heptamers. Furthermore, one would expect that the $5^{\prime}$ footprint 5-mer seen in most rearrangements would resemble the $3^{\prime}$ end of the germline sequence of the same $\mathrm{VH}$ gene that is present in the rearrangement.

\section{PRELIMINARY CONCLUSIONS AND CAVEATS FROM FOOTPRINT ANALYSIS}

Taken together, these data suggest that many if not most footprint sequences arise by some mechanism(s) other than VHR. But there are some caveats to this analysis. First, these data were only obtained on one healthy adult. It is possible that footprints may differ in other individuals or in a minority of individuals. In addition, different findings might occur in individuals with immunologic disorders such as SLE or neoplastic conditions such as B-ALL. Furthermore, only B cells from the peripheral blood were analyzed. It is conceivable that B cell populations with extensive VHR reside elsewhere in the body, particularly within the bone marrow. Finally, as discussed above, it is possible that some of the VHR footprints that were identified are due to sequencing errors. We tried to protect against this artifact by selectively analyzing unique sequences that were present in at least two copies. But even with this precaution, there are still likely to be many sequencing errors.

\section{CONCLUSION}

$\mathrm{VH}$ replacement exchanges the $\mathrm{VH}$ within a pre-existing VDJ rearrangement with an upstream $\mathrm{VH}$ gene, while preserving most of the original CDR3 sequence. It also sometimes results in the retention of a footprint sequence in the $\mathrm{VH}$ gene that was invaded. The result of VHR is an alteration in the specificity or functional status of the antibody. But the mechanistic consequence of that alteration is unclear. Is it to diversify the repertoire once a good CDR3 sequence has been found? Or is it to reduce autoreactivity or generate some form of protective multireactivity? Or is it simply a means by which B cells with non-productive rearrangements on one or both alleles have another shot at creating a productive rearrangement? In humans, the analysis of VHR is confounded by not having a means of definitively identifying the precursor rearrangement. Rather, the analysis of VHR in humans is accomplished indirectly through footprint analysis, but as demonstrated herein, footprints may arise for reasons other than VHR. Thus, while VHR certainly occurs, footprint analysis is a poor measure of its frequency because of the high rate of false positives and an unknown rate of false negatives. Nevertheless, it is possible that footprints may provide other insights into the mechanisms of $\mathrm{V}(\mathrm{D}) \mathrm{J}$ recombination and its potentially aberrant regulation in disease states. With the advent of high throughput sequencing 


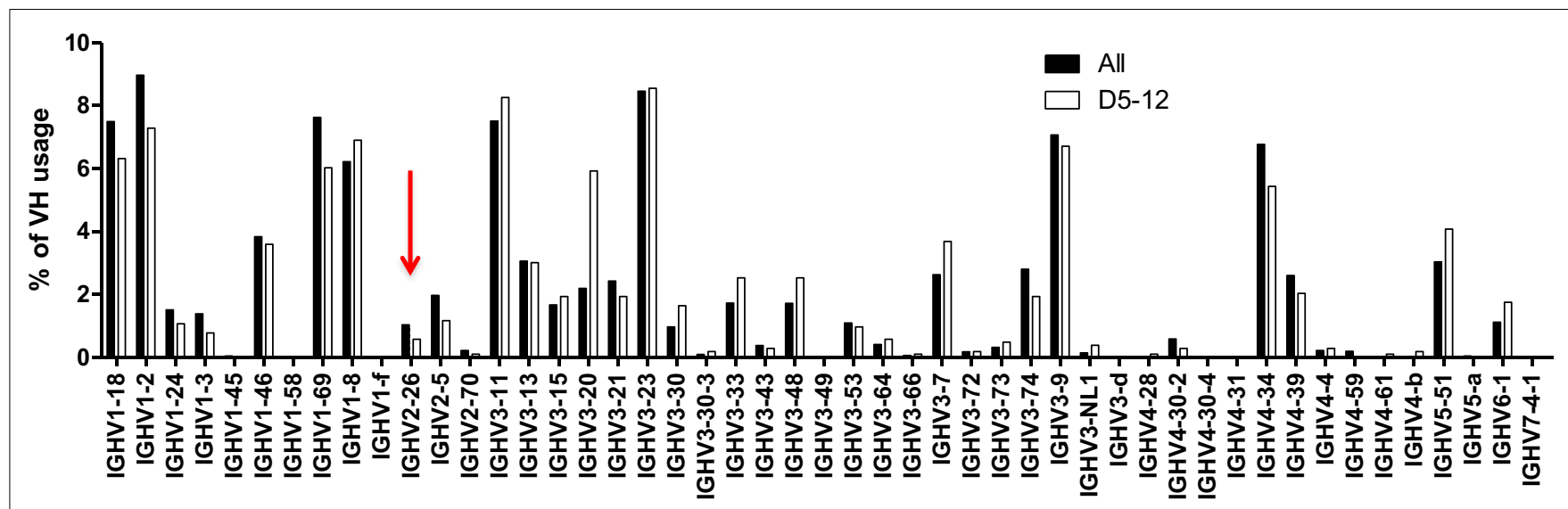

FIGURE 5 | VH usage is similar in all unique rearrangements and in rearrangements with DH5-12. VH usage is shown for total unique sequences (closed bars, $n=42,221$ ) and for those with DH5-12 (open bars, $n=1,029$ ). Sequences containing the DH5-12 gene segment in the CDR3 region were recognized using IMGT high $\mathrm{V}$ quest analysis, and further analysis on $\mathrm{VH}$ usage was performed in-house (see text). The red arrow points to $\mathrm{VH} 2-26$, which contains some of the same footprint 5-mers as DH5-12, but does not appear to be used more frequently in rearrangements that include DH5-12. studies, further analysis of $\mathrm{IgH}$ gene rearrangements for VHR and other mechanisms of CDR3 diversification promise to be illuminating.

\section{ACKNOWLEDGMENTS}

The authors acknowledge the Arthritis Foundation (Wenzhao Meng), the Lupus Research Institute (Eline T. Luning Prak), the Hematology Translational Center of Excellence at the Perelman School of Medicine of the University of Pennsylvania, NIH T32 CA009615 (Alfred L. Garfall), the Institute for Translational Medicine and Therapeutics at the University of Pennsylvania (Alfred L. Garfall) and NIH R25-DK066028 (Sahana Jayaraman) for funding this work.

\section{SUPPLEMENTARY MATERIAL}

The Supplementary Material for this article can be found online at http://www.frontiersin.org/Journal/10.3389/fimmu.2014.00010/ abstract

Figure S1 | Model for atypical open-and-shut joints. Footprint 5-mers can be generated by cleaving at the cryptic heptamer, followed by preferential trimming by exonucleolytic nibbling at the $3^{\prime}$ end of the double strand break. Shown is the generation of a footprint sequence in a VH6-1 rearrangement. The cryptic heptamer is indicated by a dashed triangle, colored squares indicate the $\mathrm{VH}$, $\mathrm{DH}$, and $\mathrm{JH}$ gene segments (not drawn to scale). According to this model, there is cleavage at the cryptic heptamer, followed by nibbling at the $3^{\prime}$ end of the break (red wavy line), leading to selective loss of the $A$ residue. The third line of the figure shows the repaired rearrangement, in which the A residue is missing from the rearrangement.

\section{REFERENCES}

1. Jung D, Giallourakis C, Mostoslavsky R, Alt FW. Mechanism and control of V(D)J recombination at the immunoglobulin heavy chain locus. Annu Rev Immunol (2006) 24:541-70. doi:10.1146/annurev.immunol.23.021704.115830

2. Gellert M. V(D)J recombination: RAG proteins, repair factors, and regulation. Annu Rev Biochem (2002) 71:101-32. doi:10.1146/annurev.biochem.71.090501. 150203

3. Vinocur JM, Fesnak AD, Liu Y, Charan D, Luning Prak ET. Violations of the 12/23 rule at the mouse immunoglobulin kappa locus, including $\mathrm{V}$ kappa-V kappa rearrangement. Mol Immunol (2009) 46:2183-9. doi:10.1016/j.molimm.2009. 04.021
4. Bassing CH, Alt FW, Hughes MM, D’Auteuil M, Wehrly TD, Woodman BB, et al. Recombination signal sequences restrict chromosomal $\mathrm{V}(\mathrm{D}) \mathrm{J}$ recombination beyond the 12/23 rule. Nature (2000) 405:583-6. doi:10.1038/35014635

5. Briney BS, Willis JR, Hicar MD, Thomas JW II, Crowe JE Jr. Frequency and genetic characterization of $\mathrm{V}(\mathrm{DD}) \mathrm{J}$ recombinants in the human peripheral blood antibody repertoire. Immunology (2012) 137:56-64. doi:10.1111/j.1365-2567. 2012.03605.x

6. Luning Prak ET, Monestier M, Eisenberg RA. B cell receptor editing in tolerance and autoimmunity. Ann N Y Acad Sci (2011) 1217:96-121. doi:10.1111/j.17496632.2010.05877.x

7. Muramatsu M, Kinoshita K, Fagarasan S, Yamada S, Shinkai Y, Honjo T. Class switch recombination and hypermutation require activation-induced cytidine deaminase (AID), a potential RNA editing enzyme. Cell (2000) 102:553-63. doi:10.1016/S0092-8674(00)00078-7

8. Reynaud CA, Garcia C, Hein WR, Weill JC. Hypermutation generating the sheep immunoglobulin repertoire is an antigen-independent process. Cell (1995) 80:115-25. doi:10.1016/0092-8674(95)90456-5

9. Darlow JM, Stott DI. Gene conversion in human rearranged immunoglobulin genes. Immunogenetics (2006) 58:511-22. doi:10.1007/s00251-006-0113-6

10. Duvvuri B, Wu GE. Gene conversion-like events in the diversification of human rearranged IGHV3-23*01 gene sequences. Front Immunol (2012) 3:158. doi:10.3389/fimmu.2012.00158

11. Darlow JM, Stott DI. V(H) replacement in rearranged immunoglobulin genes. Immunology (2005) 114:155-65. doi:10.1111/j.1365-2567.2004.02084.x

12. Kleinfield RW, Weigert MG. Analysis of VH gene replacement events in a B cell lymphoma. J Immunol (1989) 142:4475-82.

13. Chen C, Nagy Z, Luning Park ET, Weigert M. Immunoglobulin heavy chain gene replacement: a mechanism of receptor editing. Immunity (1995) 3:747-55. doi:10.1016/1074-7613(95)90064-0

14. Golub R, Martin D, Bertrand FE, Cascalho M, Wabl M, Wu GE. VH gene replacement in thymocytes. J Immunol (2001) 166:855-60.

15. Taki S, Schwenk F, Rajewsky K. Rearrangement of upstream DH and VH genes to a rearranged immunoglobulin variable region gene inserted into the DQ52$\mathrm{JH}$ region of the immunoglobulin heavy chain locus. Eur J Immunol (1995) 25:1888-96.

16. Wilson PC, Wilson K, Liu YJ, Banchereau J, Pascual V, Capra JD. Receptor revision of immunoglobulin heavy chain variable region genes in normal human $\mathrm{B}$ lymphocytes. J Exp Med (2000) 191:1881-94. doi:10.1084/jem.191.11.1881

17. Itoh K, Meffre E, Albesiano E, Farber A, Dines D, Stein P, et al. Immunoglobulin heavy chain variable region gene replacement As a mechanism for receptor revision in rheumatoid arthritis synovial tissue B lymphocytes. J Exp Med (2000) 192:1151-64. doi:10.1084/jem.192.8.1151

18. Lenze D, Greiner A, Knörr C, Anagnostopoulos I, Stein H, Hummel M. Receptor revision of immunoglobulin heavy chain genes in human MALT lymphomas. Mol Pathol (2003) 56:249-55. doi:10.1136/mp.56.5.249 
19. Ouled-Haddou H, Ghamlouch H, Regnier A, Trudel S, Herent D, Lefranc $\mathrm{M}$, et al. Characterization of a new $\mathrm{V}$ gene replacement in the absence of activation-induced cytidine deaminase and its contribution to human BCR diversity. Immunology (2014) 141:268-75. doi:10.1111/imm.12192

20. Zhang Z, Wang YH, Zemlin M, Findley HW, Bridges SL, Burrows PD, et al. Molecular mechanism of serial VH gene replacement. Ann N Y Acad Sci (2003) 987:270-3. doi:10.1111/j.1749-6632.2003.tb06060.x

21. Kowal C, Weinstein A, Diamond B. Molecular mimicry between bacterial and self antigen in a patient with systemic lupus erythematosus. Eur J Immunol (1999) 29:1901-11. doi:10.1002/(SICI)1521-4141(199906)29:06<1901::AIDIMMU1901>3.0.CO;2-L

22. Reth M, Gehrmann P, Petrac E, Wiese P. A novel VH to VHDJH joining mechanism in heavy-chain-negative (null) pre-B cells results in heavy-chain production. Nature (1986) 322:840-2. doi:10.1038/322840a0

23. Cascalho M, Wong J, Wabl M. VH gene replacement in hyperselected B cells of the quasimonoclonal mouse. J Immunol (1997) 159:5795-801.

24. Lutz J, Muller W, Jack HM. VH replacement rescues progenitor B cells with two nonproductive VDJ alleles. J Immunol (2006) 177:7007-14.

25. Rahman NS, Godderz LJ, Stray SJ, Capra JD, Rodgers KK. DNA cleavage of a cryptic recombination signal sequence by RAG1 and RAG2. Implications for partial V(H) gene replacement. J Biol Chem (2006) 281:12370-80. doi:10.1074/jbc.M507906200

26. Koralov SB, Novobrantseva TI, Konigsmann J, Ehlich A, Rajewsky K. Antibody repertoires generated by $\mathrm{VH}$ replacement and direct $\mathrm{VH}$ to $\mathrm{JH}$ joining. Immunity (2006) 25:43-53. doi:10.1016/j.immuni.2006.04.016

27. Liu Y, Li L, Kumar KR, Xie C, Lightfoot S, Zhou XJ, et al. Lupus susceptibility genes may breach tolerance to DNA by impairing receptor editing of nuclear antigen-reactive B cells. J Immunol (2007) 179:1340-52.

28. Park YH, Osmond DG. Dynamics of early B lymphocyte precursor cells in mouse bone marrow: proliferation of cells containing terminal deoxynucleotidyl transferase. Eur J Immunol (1989) 19:2139-44. doi:10.1002/eji.1830191125

29. Davila M, Liu F, Cowell LG, Lieberman AE, Heikamp E, Patel A, et al. Multiple, conserved cryptic recombination signals in $\mathrm{VH}$ gene segments: detection of cleavage products only in pro B cells. J Exp Med (2007) 204:3195-208. doi:10.1084/jem.20071224

30. Vettermann C, Herrmann K, Jack HM. Powered by pairing: the surrogate light chain amplifies immunoglobulin heavy chain signaling and pre-selects the antibody repertoire. Semin Immunol (2006) 18:44-55. doi:10.1016/j.smim.2006. 01.001

31. Keenan RA, De Riva A, Corleis B, Hepburn L, Licence S, Winkler TH, et al. Censoring of autoreactive B cell development by the pre-B cell receptor. Science (2008) 321:696-9. doi:10.1126/science.1157533

32. Ota M, Duong BH, Torkamani A, Doyle CM, Gavin AL, Ota T, et al. Regulation of the B cell receptor repertoire and self-reactivity by BAFF. J Immunol (2010) 185:4128-36. doi:10.4049/jimmunol.1002176

33. Hondowicz BD, Alexander ST, Quinn WJ III, Pagán AJ, Metzgar MH, Cancro $\mathrm{MP}$, et al. The role of BLyS/BLyS receptors in anti-chromatin B cell regulation. Int Immunol (2007) 19:465-75. doi:10.1093/intimm/dxm011

34. Liu J, Lange MD, Hong SY, Xie W, Xu K, Huang L, et al. Regulation of VH replacement by B cell receptor-mediated signaling in human immature B cells. J Immunol (2013) 190:5559-66. doi:10.4049/jimmunol.1102503

35. Sekiguchi DR, Eisenberg RA, Weigert M. Secondary heavy chain rearrangement: a mechanism for generating anti-double-stranded DNA B cells. J Exp Med (2003) 197:27-39. doi:10.1084/jem.20020737

36. Eisenberg R. The chronic graft-versus-host model of systemic autoimmunity. Curr Dir Autoimmun (2003) 6:228-44. doi:10.1159/000066864

37. Brard F, Shannon M, Luning Prak ET, Litwin S, Weigert M. Somatic mutation and light chain rearrangement generate autoimmunity in anti-singlestranded DNA transgenic MRL/lpr mice. J Exp Med (1999) 190:691-704. doi:10.1084/jem.190.5.691

38. Khan SN, Witsch EJ, Goodman NG, Panigrahi AK, Chen C, Jiang Y, et al. Editing and escape from editing in anti-DNA B cells. Proc Natl Acad Sci U S A (2008) 105:3861-6. doi:10.1073/pnas.0800025105

39. Sekiguchi DR, Yunk L, Gary D, Charan D, Srivastava B, Allman D, et al. Development and selection of edited B cells in B6.56R mice. J Immunol (2006) 176:6879-87.

40. Yunk L, Meng W, Cohen PL, Eisenberg RA, Luning Prak ET. Antibodies in a heavy chain knock-in mouse exhibit characteristics of early heavy chain rearrangement. J Immunol (2009) 183:452-61. doi:10.4049/jimmunol.0804060
41. Coleclough C, Perry RP, Karjalainen K, Weigert M. Aberrant rearrangements contribute significantly to the allelic exclusion of immunoglobulin gene expression. Nature (1981) 290:372-8. doi:10.1038/290372a0

42. Wardemann H, Yurasov S, Schaefer A, Young JW, Meffre E, Nussenzweig MC. Predominant autoantibody production by early human B cell precursors. Science (2003) 301:1374-7. doi:10.1126/science.1086907

43. Klonowski KD, Primiano LL, Monestier M. Atypical VH-D-JH rearrangements in newborn autoimmune MRL mice. J Immunol (1999) 162:1566-72.

44. Klonowski KD, Monestier M. Heavy chain revision in MRL mice: a potential mechanism for the development of autoreactive B cell precursors. J Immunol (2000) 165:4487-93.

45. Chen C, Bruderer U, Rittenberg MB. The developmental patterns of B cell precursors distinguishing between environmental and nonenvironmental forms of phosphocholine. Cell Immunol (1992) 143:378-88. doi:10.1016/0008-8749(92) 90034-M

46. Binder CJ, Hörkkö S, Dewan A, Chang MK, Kieu EP, Goodyear CS, et al. Pneumococcal vaccination decreases atherosclerotic lesion formation: molecular mimicry between Streptococcus pneumoniae and oxidized LDL. Nat Med (2003) 9:736-43. doi:10.1038/nm876

47. Watson LC, Moffatt-Blue CS, McDonald RZ, Kompfner E, Ait-Azzouzene D, Nemazee D, et al. Paucity of V-D-D-J rearrangements and VH replacement events in lupus prone and non-autoimmune $\mathrm{TdT}-/-$ and $\mathrm{TdT}+/+$ mice. $J$ Immunol (2006) 177:1120-8.

48. Eisenberg RA. Secondary receptor editing in the generation of autoimmunity. Autoimmun Rev (2012) 11:787-9. doi:10.1016/j.autrev.2012.02.004

49. Choi Y, Greenberg SJ, Du TL, Ward PM, Overturf PM, Brecher ML, et al. Clonal evolution in B-lineage acute lymphoblastic leukemia by contemporaneous $\mathrm{VH}-\mathrm{VH}$ gene replacements and $\mathrm{VH}-\mathrm{DJH}$ gene rearrangements. Blood (1996) 87:2506-12.

50. Gawad C, Pepin F, Carlton VE, Klinger M, Logan AC, Miklos DB, et al. Massive evolution of the immunoglobulin heavy chain locus in children with B precursor acute lymphoblastic leukemia. Blood (2012) 120:4407-17. doi:10.1182/blood2012-05-429811

51. van derVelden VH, Hochhaus A, Cazzaniga G, Szczepanski T, Gabert J, van Dongen JJ. Detection of minimal residual disease in hematologic malignancies by real-time quantitative PCR: principles, approaches, and laboratory aspects. Leukemia (2003) 17:1013-34. doi:10.1038/sj.leu.2402922

52. Faham M, Zheng J, Moorhead M, Carlton VE, Stow P, Coustan-Smith E, et al. Deep-sequencing approach for minimal residual disease detection in acute lymphoblastic leukemia. Blood (2012) 120:5173-80. doi:10.1182/blood-2012-07444042

53. Zhang Z, Zemlin M, Wang YH, Munfus D, Huye LE, Findley HW, et al. Contribution of $\mathrm{Vh}$ gene replacement to the primary $\mathrm{B}$ cell repertoire. Immunity (2003) 19:21-31. doi:10.1016/S1074-7613(03)00170-5

54. Lefranc MP, Giudicelli V, Ginestoux C, Jabado-Michaloud J, Folch G, Bellahcene F, et al. IMGT, the international ImMunoGeneTics information system. Nucleic Acids Res (2009) 37:D1006-12. doi:10.1093/nar/gkn838

Conflict of Interest Statement: Dr. Christopher S. Carlson is affiliated with Adaptive Biotechnologies, a for-profit high throughput sequencing company. The high throughput sequencing data that were analyzed for this paper were, however, generated at the University of Pennsylvania, not at Adaptive Biotechnologies. The other co-authors declare that the research was conducted in the absence of any commercial or financial relationships that could be construed as a potential conflict of interest.

Received: 29 October 2013; accepted: 07 January 2014; published online: 30 January 2014.

Citation: Meng W, Jayaraman S, Zhang B, Schwartz GW, Daber RD, Hershberg U, Garfall AL, Carlson CS and Luning Prak ET (2014) Trials and tribulations with VH replacement. Front. Immunol. 5:10. doi: 10.3389/fimmu.2014.00010

This article was submitted to B Cell Biology, a section of the journal Frontiers in Immunology.

Copyright (C) 2014 Meng, Jayaraman, Zhang, Schwartz, Daber, Hershberg, Garfall, Carlson and Luning Prak. This is an open-access article distributed under the terms of the Creative Commons Attribution License (CC BY). The use, distribution or reproduction in other forums is permitted, provided the original author(s) or licensor are credited and that the original publication in this journal is cited, in accordance with accepted academic practice. No use, distribution or reproduction is permitted which does not comply with these terms. 